\title{
Bioreducible PEI-siRNA Nanocomplex for Liver Cancer Therapy: Transfection, Biodistribution, and Tumor Growth Inhibition In Vivo
}

\author{
Wei Xia, ${ }^{1,2}$ Yan Li, ${ }^{3}$ Bo Lou, ${ }^{4,5}$ Peijun Wang, ${ }^{1}$ Xiaolong Gao, ${ }^{1}$ and Chao Lin $^{4}$ \\ ${ }^{1}$ Department of Imaging, Tongji Hospital, Tongji University, Shanghai 200065, China \\ ${ }^{2}$ Department of Nuclear Medicine, Shanghai Seventh People's Hospital, Shanghai 200137, China \\ ${ }^{3}$ Translational Medicine Research Centre and Central Laboratory, Shanghai First Maternity and Infant Hospital, School of Medicine, \\ Tongji University, Shanghai 200040, China \\ ${ }^{4}$ The Institute for Advanced Materials and Nano Biomedicine, School of Medicine, Tongji University, Shanghai 200092, China \\ ${ }^{5}$ School of Life Sciences and Technology, Tongji University, Shanghai 200092, China
}

Correspondence should be addressed to Peijun Wang; tongjipjwang@vip.sina.com and Chao Lin; chaolin@tongji.edu.cn

Received 21 May 2012; Revised 11 December 2012; Accepted 11 December 2012

Academic Editor: Takuya Tsuzuki

Copyright (c) 2013 Wei Xia et al. This is an open access article distributed under the Creative Commons Attribution License, which permits unrestricted use, distribution, and reproduction in any medium, provided the original work is properly cited.

\begin{abstract}
A bioreducible polyethylenimine (SS-PEI) was successfully applied as a nonviral carrier for the delivery of plasmid DNA and VEGFsiRNA in vitro and in vivo. The SS-PEI could strongly condense DNA or siRNA into nanosized complexes (below $200 \mathrm{~nm}$ ) with positive surface charges. In vitro transfection experiments using GFP plasmid as gene reporter showed that the complexes of SSPEI/DNA were able to efficiently transfect HepG2 cells, with efficiency comparable to that of polyethylenimine, a gold standard for nonviral gene delivery. Moreover, the complexes of SS-PEI/VEGF-siRNA could lead to reduced levels of VEGF protein in HepG2 cells in vitro. Treatment with the complexes of SS-PEI/VEGF-siRNA efficiently inhibited HepG2 tumor growth in an xenograft mouse model. The data of this study imply that the SS-PEI is a potent nucleic acid carrier applicable for liver cancer gene therapy.
\end{abstract}

\section{Introduction}

Hepatocellular carcinoma (HCC) is the fifth common cancer in the world. Due to the lack of an early clinical diagnosis method and obvious symptoms, HCC tumor is regularly detected at advanced stages. Although surgical operation on tumor removal is generally helpful for HCC patients, clinical mortality of HCC is relatively high because therapeutic options of HCC are rather limited [1,2]. Besides, traditional chemotherapy using anticancer drugs is inefficacious for HCC patients. It has been known that HCC progression is closely associated with HCC tumor angiogenesis which is upregulated by the vascular endothelial growth factor (VEGF) from the tumor cells [3, 4]. Additionally, VEGF, mainly VEGF-A, may activate quiescent endothelial cells in a paracrine manner and subsequently promote their migration, proliferation, and differentiation [5, 6]. An enhanced level of VEGF in HCC tumor thus typically leads to increase of HCC tumor size. Therefore, inhibiting VEGF levels of HCC tumor cells has been proposed as an applicable strategy for HCC therapy [7].

Small-interfering-RNA-(siRNA-) induced RNA interference (RNAi) presents an effective and simple method to silence a wide range of cancer-associated genes. SiRNA-based therapy has revealed a great promise for human cancer therapy in the past decade [8]. An intrinsic mechanism of siRNAinduced gene silencing process comprises the incorporation of 21-23 nucleotide siRNA duplexes into an active RNAinduced silencing complex, which can recognize and cleave mRNA target. Moreover, a number of 21-nucleotide siRNAs have been established that are capable of knocking down different types of human cancer gene targets including VEGF, a primary angiogenic factor often detected in developed HCC [9]. Raskopf et al. recently reported that siRNA targeting VEGF can inhibit functional properties of endothelial cells in vitro and HCC tumor growth in vivo [10]. However, 
the success of RNAi for cancer therapy remains a big challenge due to the lack of low-toxic and highly efficient siRNA delivery carriers [11]. Cationic polymers have emerged as siRNA delivery carriers in recent years [11-13]. Compared to traditional recombinant viral vectors, cationic polymers take many favorable merits such as low immune response, handy modification, large-scale manufacturing, and low cost. Polyethylenimine (PEI) is one of the most studied siRNA delivery carriers since it has those favorable biophysical properties for siRNA delivery, including the ability to bind negatively charged siRNAs to form nanoscale complexes and high buffer capacity for facilitated endosomal escape of the complexes [14]. However, PEI has been found to be highly toxic, due to the nature of nondegradability, thus seriously hampering further clinical applications. We have recently reported that a biodegradable PEI with disulfide bonds (SSPEI) is highly potent for the delivery of siRNA targeting human telomerase reverse transcriptase (hTERT), giving rise to the silencing of hTERT gene expression in different types of human cancer cell lines. Also, the SS-PEI has practically low cytotoxicity profile than nondegradable PEI in vitro and in vivo, including inducing low percentages of apoptotic HepG2 cells in vitro and no adverse effect on liver and kidney functions in vivo at an i.v. dose of $50 \mu \mathrm{g} / \mathrm{kg}[15,16]$.

In this study, we hypothesize that the SS-PEI can serve as a siRNA carrier for the delivery of siRNA targeting VEGF in vitro and in vivo. Thus, we examined biophysical properties of SS-PEI/VEGF-siRNA complexes, in vivo biodistribution of the complexes, siRNA transfection in vitro and in vivo, and growth inhibition of HCC tumor bearing in a nude mouse model. It was found that the complexes of SS-PEI/VEGFsiRNA can efficiently downregulate the VEGF protein levels in HepG2 cells in vitro and in vivo and also induce remarkable inhibition of HepG2 tumor growth in vivo.

\section{Materials and Method}

2.1. Materials. All chemicals, low molecular weight polyethylenimine (LWPEI, $800 \mathrm{Da}$ ), N-Hydroxysuccinimide (NHS), 1-(3-Dimethylaminopropyl)-3-ethylcarbodiimide (EDC), and 3 '-dithiobispropanoic acid (DTPA) were ordered from Aldrich-Sigma. Linear polyethylenimine (ExGen 500, $M_{w}=25 \mathrm{kDa}$ ) was ordered from Fermentas (Germany). Near-infrared fluorescent Cy5.5 dye was ordered from Beijing FanBo Co., PR. China. SiRNA were purchased and synthesized by GenePharma Company, Shanghai, China, the GFP-siRNA (sense: 5 -AACUUCAGGGUCAGCUUGCdTdT- ${ }^{\prime}$ ) and the VEGF siRNA (sense: 5 -GGAGUACCCUGAUGAGAUCdTdT-3 ).

2.2. Synthesis of Bioreducible Polyethylenimine (SS-PEI) and Cy5.5-Labeled SS-PEI. SS-PEI $\left(M_{w}=8.5 \mathrm{kDa}\right.$, PDI $\left.=1.8\right)$ was obtained by coupling of 3 -dithiobispropanoic acid (DTPA) with LWPEI $(800 \mathrm{Da})$ at an equal molar ratio via an EDC/NHS activation reaction, as the reported previously [15]. In brief, DTPA ( $2 \mathrm{mmol}, 0.42 \mathrm{~g})$, LWPEI ( $2 \mathrm{mmol}, 1.60 \mathrm{~g})$, EDC ( $5 \mathrm{mmol}, 0.96 \mathrm{~g}$ ), and NHS (5 mmol,
$0.57 \mathrm{~g})$ were added into a reaction flask and stirred in 2-(N-morpholino)ethanesulfonic acid (MES) buffer ( $\mathrm{pH}$ 6.5, $5 \mathrm{~mL}$ ). The reaction was performed at room temperature under nitrogen atmosphere. The reaction mixture was allowed to proceed for 2 days, yielding a viscous solution. Next, the resulting solution was purified by exhaustive dialysis $(3500 \mathrm{~g} / \mathrm{mol}$ cut-off) with $50 \mathrm{mM} \mathrm{NaCl}$ solution $(3 \times 5 \mathrm{~L})$ and then deionized water for 3 days. SS-PEI polymer was finally collected as a solid powder after freeze drying (yield: 25\%).

Cy5.5-labeled SS-PEI was prepared by coupling NHSactivated Cy5.5 with SS-PEI. In brief, SS-PEI $(50 \mathrm{mg})$ and NHS-Cy5.5 (200 nmol in DMSO) were added into a reaction flask and stirred in MES buffer ( $\mathrm{pH} 6.5,5 \mathrm{~mL}$ ). The reaction was allowed to proceed for 2 days at room temperature. The resulting solution was then purified by exhaustive dialysis ( $3500 \mathrm{~g} / \mathrm{mol}$ cut-off) for 3 days. Cy5.5-labeled SS-PEI was finally collected as a solid powder after freeze drying (yield: $78 \%)$. The content of Cy5.5 in SS-PEI $(65.5 \mathrm{pmol} / \mu \mathrm{g})$ was calculated using a calibration curve derived from a series of Cy5.5 solutions at different concentrations.

2.3. Agarose Gel Retardation. SS-PEI/DNA complexes were prepared by adding a HEPES buffer solution $(20 \mathrm{mM}, \mathrm{pH}$ 7.4) of SS-PEI $(10 \mu \mathrm{L}$, varying concentrations) to a HEPES solution of DNA $(10 \mu \mathrm{L}, 80 \mu \mathrm{g} / \mathrm{mL})$, followed by vortexing for $5 \mathrm{~s}$, and the dispersions were incubated for $30 \mathrm{~min}$ at room temperature. After addition of $2 \mu \mathrm{L}$ of $6 \mathrm{x}$ loading buffer (Fermentas), $10 \mu \mathrm{L}$ of this mixture was applied onto a $0.7 \%$ agarose gel containing ethidium bromide. After development of the gel, DNA was visualized with a UV lamp using a Tanon Gel system (Tanon Gel Image System, Thermo Scientific).

2.4. Particle Size and Zeta-Potential Measurements. SS-PEI/ DNA complexes were prepared by adding a HEPES buffer solution $(20 \mathrm{mM}, \mathrm{pH} 7.4)$ of SS-PEI $(800 \mu \mathrm{L}$, varying concentration) to a HEPES solution of DNA $(200 \mu \mathrm{L}, 20 \mu \mathrm{g} / \mathrm{mL})$, followed by vortexing for $5 \mathrm{~s}$, and incubating at room temperature for $30 \mathrm{~min}$. The particle size and surface charge of formed complexes were measured at $25^{\circ} \mathrm{C}$ with a Nanosizer NS90 (Malvern Instruments Ltd., Malvern, UK).

2.5. Cell Culture. HepG2 cells (ATCC, USA) and SGC7901 cells stably expressing green fluorescent protein (GFP) (offered by Shanghai Chinese Academy, PR China) were grown in full culture growth medium (i.e., DMEM supplemented with $10 \%$ FBS (GIBCO), $100 \mathrm{U} / \mathrm{mL}$ penicillin, and streptomycin $(\mathrm{GIBCO}))$ at $37^{\circ} \mathrm{C}$ in a humidified $5 \% \mathrm{CO}_{2}$ containing atmosphere.

\subsection{DNA/siRNA Transfection In Vitro, Gene Expression, and Cell Viability Assay}

2.6.1. DNA Transfection against HepG2 Cells. HepG2 cells $\left(7 \times 10^{4}\right.$ cells/well $)$ were plated in 24 -well plate and allowed to grow at least $24 \mathrm{~h}$ until $60-70 \%$ cell confluence until transfection. In a typical DNA transfection [17, 18], SS-PEI and DNA $(1 \mu \mathrm{g})$ were gently mixed in HEPES buffer $(20 \mathrm{mM}$, 
$\mathrm{pH}$ 7.4) and incubated at an ambient temperature for 30 minutes. The $N / P$ ratios of SS-PEI and DNA were varied from $1 / 1$ to $32 / 1$. Next, the cells were washed twice with PBS buffer, serum-free DMEM medium $(500 \mu \mathrm{L})$ was added, and then the diluted DNA mixture (total $50 \mu \mathrm{L}$ ) was gently added into the 24-well plate for $1 \mathrm{~h}$ transfection. After which, the medium was replaced with full culture growth medium, and the cells were cultured for another $47 \mathrm{~h}$.

2.6.2. SSPEI-Mediated siRNA Transfection Targeting GFP Gene in SGC7901 Cells. SGC-7901 cells stably expressing GFP $\left(7 \times 10^{4}\right.$ cells/well $)$ were plated in 24 -well plate and allowed to grow at least $24 \mathrm{~h}$ until $60-70 \%$ cell confluence until transfection. In a typical GFP-siRNA transfection, SSPEI (in sterilized HEPES buffer, $20 \mathrm{mM}, \mathrm{pH}$ 7.4) and siRNA $(0.5 \mu \mathrm{g}$ in DEPC water) were gently mixed at varying $N / P$ ratios ranging from $2 / 1$ to $16 / 1$ and incubated at an ambient temperature for $30 \mathrm{~min}$. SGC-7901 cells were then washed twice with PBS buffer, serum-free DMEM medium $(500 \mu \mathrm{L})$ was added, and then the diluted siRNA mixture (total $10 \mu \mathrm{L}$ ) was gently added into the 24 -well plate for $1 \mathrm{~h}$ transfection. After which, the medium was replaced with full medium, and the cells were cultured for another $23 \mathrm{~h}$.

2.6.3. SSPEI-Mediated siRNA Transfection Targeting VEGF Gene in HepG2 Cells. HepG2 cells $\left(1.5 \times 10^{5}\right.$ cells/well $)$ were plated in a 6-well plate and allowed to grow at least $24 \mathrm{~h}$ until $60-70 \%$ cell confluence. In a typical VEGF-siRNA transfection, SS-PEI (in sterilized HEPES buffer, $20 \mathrm{mM}, \mathrm{pH}$ 7.4) and siRNA (5 $\mu \mathrm{g}$ in DEPC water) at an optimal $N / P$ ratios of $12 / 1$ were gently mixed and incubated at an ambient temperature for $30 \mathrm{~min}$. HepG2 cells were then washed twice with PBS buffer, serum-free DMEM medium $(500 \mu \mathrm{L})$ was added, and then the diluted siRNA mixture was gently added into the 6 -well plate for $4 \mathrm{~h}$ transfection. After which, the medium was replaced with fresh full medium. After additional $6 \mathrm{~h}$ of incubation, the medium was replaced again with fresh full medium. After another $14 \mathrm{~h}$, the conditioned medium was collected to determine the amount of VEGF secreted from the cells by ELISA assay (Quantikine human VEGF immunodetection kit, R\&D systems, Minneapolis, $\mathrm{MN}$, USA), according to the manufacturer's instruction.

2.6.4. Cell Uptake of FAM-siRNA in HepG2 Cells. Fluorescence microscopy was used to evaluate intracellular trafficking of siRNA. HepG2 cells $\left(7 \times 10^{4}\right)$ were seeded on a coverslip in a 24-well plate and allowed to grow at least $24 \mathrm{~h}$. Next, complexes of SS-PEI and FAM-siRNA were gently mixed and incubated at an ambient temperature for $30 \mathrm{~min}$. HepG2 cells were then washed twice with PBS buffer, and serum-free DMEM medium $(500 \mu \mathrm{L})$ was added. Then, the complexes of SS-PEI/FAM-siRNA (100 nM) were added into the wells for $3 \mathrm{~h}$ incubation. Finally, the treated cells were washed twice with PBS buffer and observed under fluorescence microscopy (Nikon).

2.6.5. EGFP Expression Analysis. The fluorescence intensity was measured to quantify GFP gene expression in cells. Cells in each well were washed twice with PBS and incubated with cell lysis buffer $(200 \mu \mathrm{L})$. The cell lysates were collected, centrifuged to pellet the cellular debris, and $100 \mu \mathrm{L}$ of cell lysate was used to determine fluorescence intensity of GFP with excitation and emission wavelengths of 488 and $520 \mathrm{~nm}$, respectively (Thermo Scientific). Background fluorescence and autofluorescence were determined using untreated cells as a blank control. The total recovered protein concentration in cell lysate from each well was estimated using BAC protein assay kit (Invitrogen) by taking BSA as a standard. The amount of protein was estimated from a standard bovine serum albumin curve. GFP expression was calculated as fluorescence intensity (FI) normalized against protein concentration and presented as arbitrary units (A.U.)/mg protein, and results represent mean \pm standard deviation for triplicate samples.

2.6.6. Cell Viability Assay. The cell viability was measured using an Alamar Blue assay [17, 19, 20]. In detail, the cells (including untreated cells) were washed twice with PBS buffer and incubated with fresh-made $2 \mathrm{~mL}$ of $1 \times$ Alamar Blue-RPMI 1640 media (i.e., 10-fold diluted Alamar Blue solution in RPMI 1640 medium) for $4 \mathrm{~h}$. Then, $200 \mu \mathrm{L}$ of the medium from each well (and also $1 \times$ Alamar BlueRPMI 1640 medium as a blank) was transferred to a 96well plate for recording. The absorbance densities (ODs) were measured using a plate reader (Thermo Scientific) at wavelength of $570 \mathrm{~nm}$ and $630 \mathrm{~nm}$, respectively. Cell viability was calculated with the equation: Cell viability (\%) = $\left(\mathrm{OD}_{\text {sample }}-\mathrm{OD}_{0}\right) /\left(\mathrm{OD}_{\text {control }}-\mathrm{OD}_{0}\right) \times 100$, wherein $\mathrm{OD}_{\text {sample }}$, $\mathrm{OD}_{\text {control }}$, and $\mathrm{OD}_{0}$ represent the $\mathrm{OD}$ values of the medium of transfected cells, the medium of untreated cells, and $1 \times$ Alamar Blue-RPMI 1640 medium as a blank, respectively. The calculated value for untreated cells as a control was taken as $100 \%$ cell viability.

\subsection{Noninvasive Tumor Imaging and Accumulation of SS-PEI} in a Mouse Model. The animal experiments were officially approved by Affiliated Tongji Hospital of Tongji University (Shanghai, China). 5-6 week-old male BALB/c nude mice were purchased from SLAC Laboratory Animals (Shanghai, China). HepG2 tumors were induced in the mice by subcutaneously injecting HepG2 cells $\left(5.0 \times 10^{6}\right)$ into the flank of the mice. When the tumor volume has reached to approximately $400 \mathrm{~mm}^{3}$, the complexes of Cy5.5-labeled SS$\mathrm{PEI} / \mathrm{GFP}$-siRNA $(N / P=12 / 1)$ were i.v. administrated by tailvein injection. The total amount of Cy5.5 in the polyplexes was calculated to be $960 \mathrm{pmol}$, as determined by a routine UV-calibration method. The administered GFP-siRNA is $10 \mu \mathrm{g}$ for each mouse. At regular time intervals, the tumor site was scanned for in vivo fluorescence imaging with quantitative fluorescence molecular tomography (FMT) imaging system (Visen, USA). Excitation and emission wavelengths used for Cy5.5 imaging were 670 and 690-740 nm, respectively.

When imaging organs, the mice were scarified after $24 \mathrm{hr}$ postinjection. The organs such as heart, lungs, liver, spleen, and kidneys were collected for ex vivo imaging with the FMT imaging system. The amount of Cy5.5 in tumor and each organ was determined using the software (version), according 
to the manufacture's instruction. The tumor (or organ) accumulation of SS-PEI was calculated as the percentage of the amount of Cy5.5 in the tumor compared to the total amount of Cy5.5 (960 pmol) prior to injection. The data are presented as the means \pm SD values of triplicate samples in three independent experiments.

\subsection{SS-PEI-Mediated VEGF-siRNA Transfection in HepG2} Tumor. 5-6-week-old male BALB/c nude mice were purchased from SLAC Laboratory Animals (Shanghai, China) and divided into four groups with 5 mice in each group: untreated group, VEGF siRNA group using SS-PEI, VEGF siRNA-NC group using SS-PEI, and VEGF siRNA group using $25 \mathrm{kDa}-\mathrm{PEI}$ (B-PEI) as a positive control. HepG2 tumors were induced in the mice by subcutaneously injecting HepG2 cells $\left(5.0 \times 10^{6}\right)$ into the flank of the mice. When the tumor volume has reached to approximately $200 \mathrm{~mm}^{3}$, SS$\mathrm{PEI} /$ siRNA complexes, B-PEI/siRNA complexes, or PBS as a blank control were, respectively, injected into the tumor at multiple site ( 6 points). The amount of siRNA is $40 \mu \mathrm{g}$ in the complexes at an optimal $N / P$ ratio of $12 / 1$. Tumor size was monitored every 7 days. The tumor volume was measured with digital caliper in two dimensions and calculated as the formula: (length) $\times(\text { width })^{2} / 2$.

\subsection{Immunohistochemistry Evaluation of Proliferation in} Tumor. Tumor specimens were sectioned and stained with hematoxylin and eosin (HE), VEGF or CD34, as per standard protocols. For VEGF staining, tumor sections were incubated with rabbit anti-VEGF antibody (Invitrogen), followed by a biotinylated goat anti-rabbit secondary antibody (Vector Laboratories). For CD34 staining, tumor sections were incubated with rabbit anti-CD34 antibody (Invitrogen), followed by a biotinylated goat anti-rabbit secondary antibody (Vector Laboratories). The sections are finally stained with the Vectastain ABC Elite Kit (Vector Laboratories). The nuclei were counterstained with haematoxylin.

2.10. Statistical Analysis. Analysis was performed using the Statistical Program for Social Science (SPSS) for Windows (SPSS Inc., USA). Differences were considered to be statistically significant at $P<0.05$ (Student's $t$-test).

\section{Results}

3.1. Biophysical Characterization of SS-PEI/DNA and SSEPI/siRNA Complexes. The structure of SS-PEI contains multiple low molecular $800 \mathrm{Da}-\mathrm{PEI}$ that is linked with reversible disulfide bonds (Figure 1(a)). To ascertain whether the SS-PEI may bind gene and siRNA, gel retardation shift assay was conducted after incubating different amounts of SSPEI with a constant amount of DNA or siRNA. Figure 1(b) reveals the capability of SS-PEI to bind DNA as a function of $N / P$ ratio. When the ratio was increased from $1 / 8$ to $12 / 1$, the mobility of DNA was completely retarded at and above an $N / P$ ratio of $4 / 1$, indicating the complexation of SS-PEI with DNA. In order to further validate the complexation, dynamic light scattering (DLS) was applied to characterize the particle sizes and surface charges of SS-PEI/DNA complexes. It was shown that the SS-PEI condensed DNA into nanoscale complexes with an average diameter ranging from about $95 \mathrm{~nm}$ to $170 \mathrm{~nm}$ (Figure 1(c)). The complexes revealed unimodel size distribution (Figure 1(d)). Besides, the complexes exhibited positive surface charges. When increasing $N / P$ ratios from $3 / 1$ to $24 / 1$, the surface charges enhanced from +16 to $+23 \mathrm{mV}$ (Figure $1(\mathrm{c})$ ), indicating that an exterior, SS-PEI-based corona exists in the complexes. The binding of SS-PEI with siRNA was also examined. The results in Figure 1(e) imply that the SS-PEI is capable of condensing siRNA efficiently. Agarose gel retardation assay showed that SS-PEI totally retarded siRNA mobility at and above an $N / P$ ratio of $8 / 1$. DLS measurement further revealed that nanoscale complexes of SS-PEI/siRNA were formed at and above $N / P$ ratio of $3 / 1$ with average diameters below $200 \mathrm{~nm}$ (Figure 1(f)). At a low $N / P$ ratio of $3 / 1$, the complex of SS-PEI/siRNA had negative surface charge. When the $N / P$ ratios were increased to $6 / 1$ or higher, positive surface charges $(>+22 \mathrm{mV})$ were obtained for the complexes.

\subsection{SS-PEI Mediates Efficient DNA Transfection in HepG2} Cells In Vitro. The transfection of SS-PEI/DNA complexes was studied in vitro by using HepG2 cell line and the plasmid pCMV-GFP as reporter gene. First, the effect of $N / P$ ratio on gene transfection was evaluated by measuring the levels of GFP gene expression at different $N / P$ ratios (Figure $2(a))$. In general, gene transfection efficiency remarkably increased when $N / P$ ratios were increased from $1 / 1$ to $32 / 1$. At an $N / P$ ratio of $32 / 1$, the complexes could lead to potent transfection with an efficiency that is comparable to that of the complexes from 25-kDa linear PEI (ExGen 500), prepared at an optimal $N / P$ ratio of $10 / 1$, as a positive control. Importantly, SS-PEI-based complexes revealed low cytotoxicity at the polymer/DNA ratios from $1 / 1$ to $32 / 1$, where at least $80 \%$ cells retain their metabolic activity (Figure 2(b)). By contrast, complexes of PEI are more cytotoxic than those of SSPEI (about 70\% cells maintaining metabolic activity, $P<0.05)$. Figure $2(\mathrm{c})$ shows typical HepG2 cells expressing GFP observed under fluorescence microscopy after the cells are transfected by the complexes of SS-PEI and PEI, respectively. The percentage of GFP positive cells was also quantified with flow cytometry. At their optimal $N / P$ ratios, the complexes of SS-PEI again induced transfection efficiency comparable to those of 25-kDa PEI (ExGen 500), that is, $25.2 \pm 2.3 \%$ and $33.8 \pm 3.1 \%$ of GFP-positive cells.

3.3. SS-PEI-Delivered siRNA Induces Gene Silencing In Vitro. To ascertain whether SS-PEI can mediate siRNA delivery to silence GFP gene expression, the transfection of SS-PEI was performed in vitro by using SGC-7901 cells stably expressing GFP gene. The silencing efficiencies were optimized as a function of $N / P$ ratios in the range from $2 / 1$ to $16 / 1$ (Figure $3(\mathrm{a})$ ). It was showed that, at an optimal $N / P$ ratio of $12 / 1$, the complexes of SS-PEI/GFP-RNA efficiently transfected the SCG cells, with the gene silencing efficiency that is $42 \pm 1.5 \%$ 


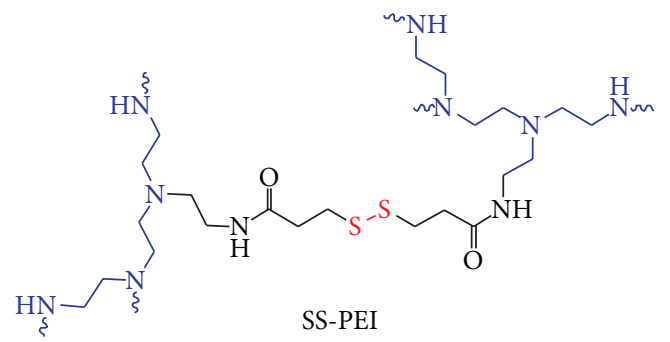

(a)

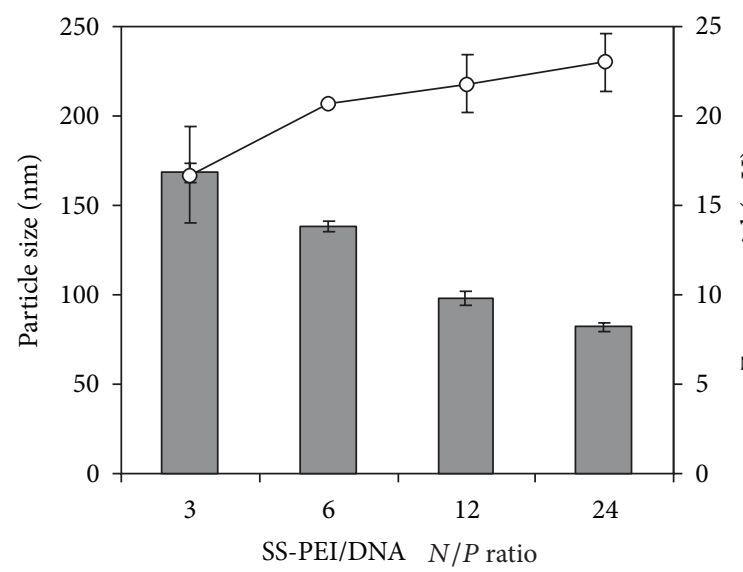

(c)

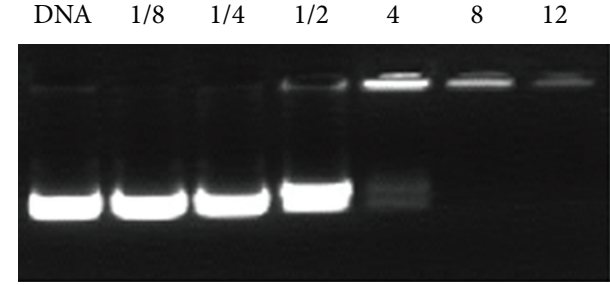

(b)

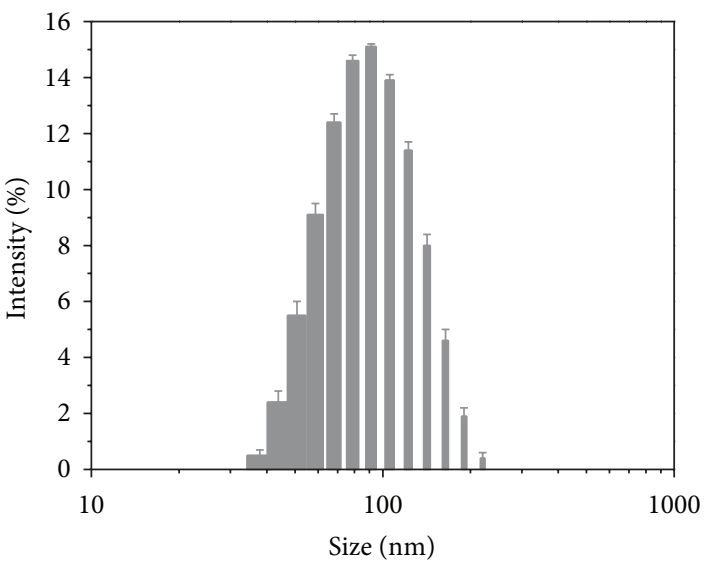

(d)

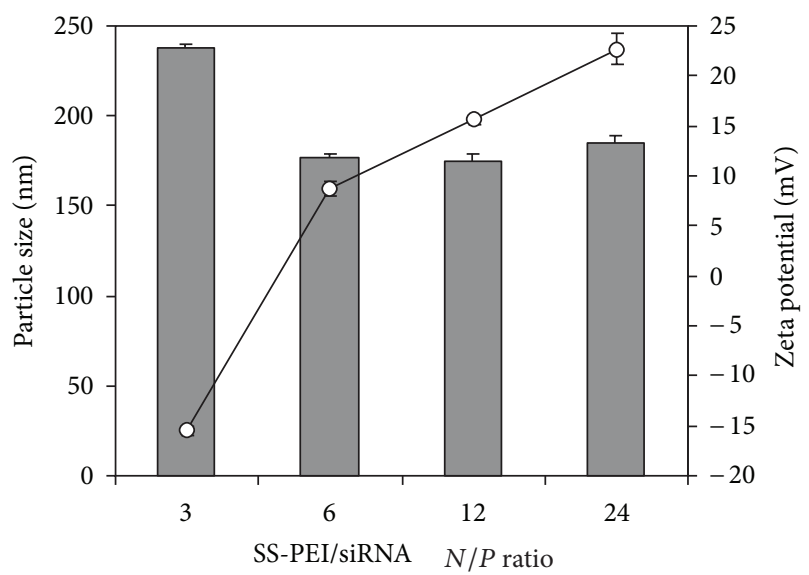

(f)

FIGURE 1: (a) Chemical structure of bioreducible polyethylenimine (SS-PEI); (b) gel retardation assay on the binding of SS-PEI with plasmid gene; (c) and (d) dynamic light scattering analysis on the size, size distribution, and surface charge of SS-PEI/DNA complexes; (e) gel retardation assay on the binding of SS-PEI with VEGF-siRNA; (f) dynamic light scattering analysis on the size and surface charge of SS$\mathrm{PEI} / \mathrm{siRNA}$ complexes.

residual level of GFP expression compared to the blank control. By contrast, either SS-PEI alone or the complexes of SS$\mathrm{PEI} /$ siRNA-NC failed to significantly reduce the level of GFP expression. Besides, the complexes of SS-PEI/siRNA showed low cytotoxicity against SGC-7901 cells in vitro with more than $85 \%$ metabolic activity. It was thought that this efficient GFP gene silencing should be correlated with efficient siRNA internalization. Thus, fluorescein-amidite-(FAM-) labeled siRNA was used to study the cellular uptake of free siRNA and the complexes against HepG2 cells. The fluorescence image in Figure 3(e) shows that green fluorescence was observed in the cells treated with SS-PEI/FAM-siRNA complexes, suggesting efficient internalization of the siRNA. Besides, fluorescenceactivated cell sorting (FACS) measurement showed that ca. $86.5 \pm 2.5 \%$ cells are FAM positive (Figure $3(\mathrm{~d})$ ). This high cell uptake efficiency may be the reason why SS-PEI/siRNA complexes induce high silencing efficiency in gene knockdown experiments. On the contrary, no green fluorescence 


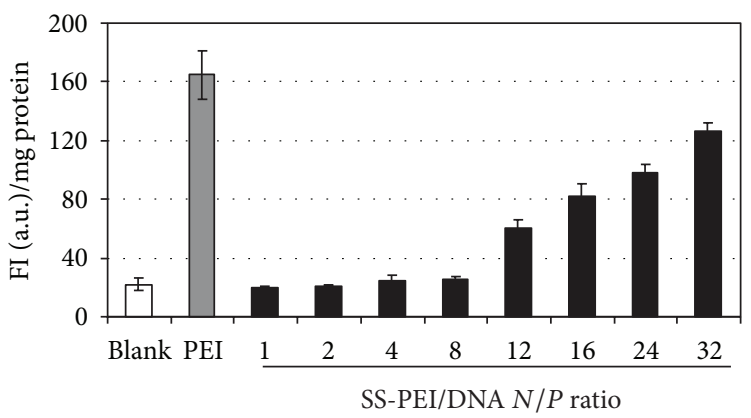

(A)

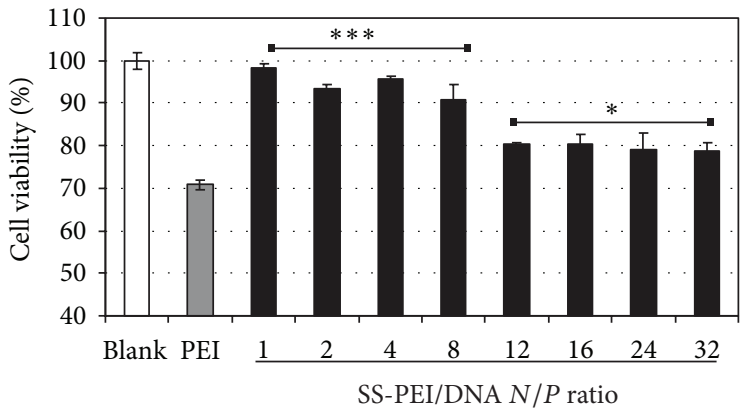

(B)

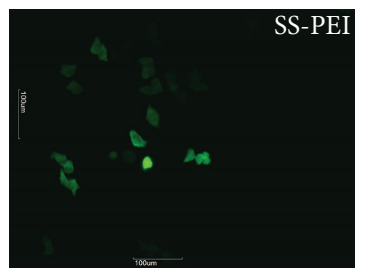

(a)

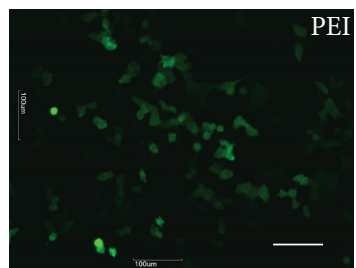

(c)

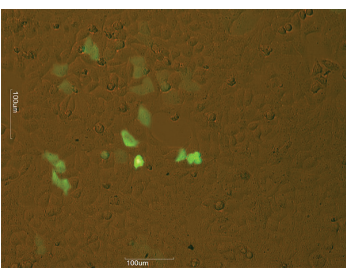

(b)

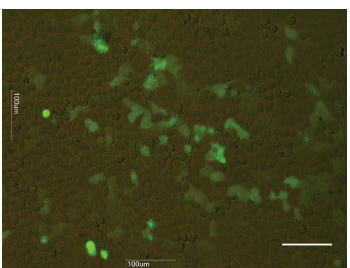

(d)

(C)

Figure 2: SS-PEI-mediated plasmid DNA transfection in HepG2 cells in vitro. (A) Effect of the N/P ratios on the gene expression levels in HepG2 cells. $25 \mathrm{kDa}$-branched PEI was used as a control; (B) cell viability of SS-PEI/DNA complexes in HepG2 cells at varying N/P ratios. The percentage of relative cell viability was determined relative to control cells (untreated), taken as 100\% cell viability. $25 \mathrm{kDa}$-branched PEI was used as a control. ${ }^{* * *} P<0.001,{ }^{*} P<0.05$ : SS-PEI versus PEI; (C) typical HepG2 cells expressing GFP observed under fluorescence microscopy after gene transfection with SS-PEI (a and b) and $25 \mathrm{kDa}$ PEI (ExGen 500) (c and d). (Scale bar: $50 \mu \mathrm{m}$ ).

was detectable in the HepG2 cells treated with free FAMsiRNA due to its poor cell uptake (data not shown). We next examined the possibility of SS-PEI for the delivery of siRNA targeting vascular endothelial growth factor (VEGF), an inducer of angiogenesis, in HepG2 cells. The VEGF expression was quantified with ELISA kit after VEGF-siRNA transfection. It was found that, at an optimal $N / P$ ratio of 12/1, SS-PEI/VEGF-siRNA could potently transfect HepG2 cells, with VEGF gene silencing efficiency comparable to that treated by Lipofectamine 2000/VEGF-siRNA as a positive control (17.1 $\pm 1.3 \%$ versus $11.7 \pm 1.4 \%$ residual VEGF protein level compared to the blank control, Figure 3(c)).

3.4. Organ Accumulation of SS-PEI in Tumor-Bearing Nude Mouse. Biodistribution of SS-PEI was investigated after the complexes of cy5.5-labelled SS-PEI/siRNA were i.v. administrated into a tumor-bearing nude mouse by tail-vein injection. It was shown that the amount of SS-PEI in the tumor increased in early stage and then significantly reduced with postinjection time from 0.1 to $24 \mathrm{~h}$ (Figures $4(\mathrm{a})$ and $4(\mathrm{~b})$ ). 


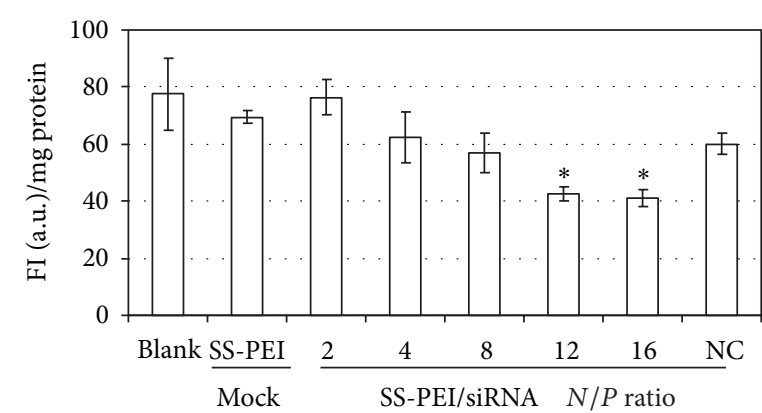

(a)

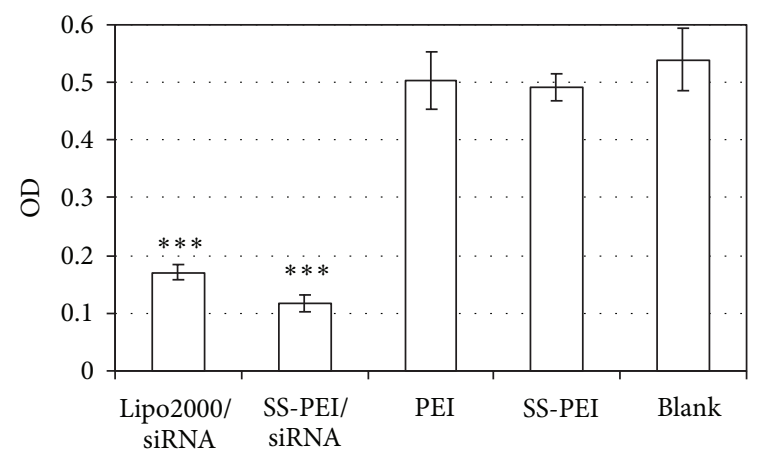

(c)

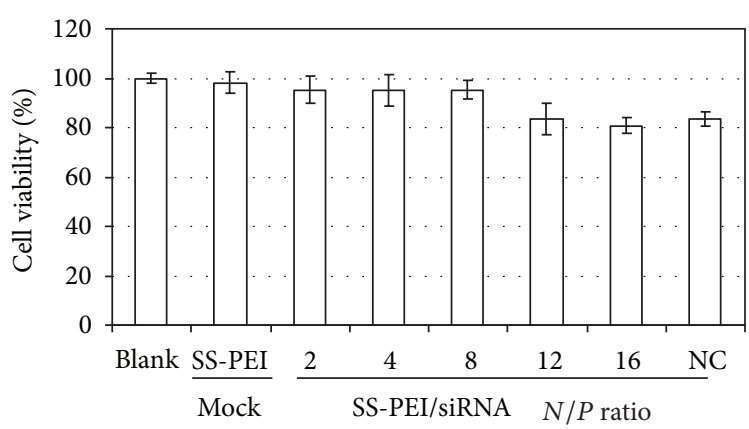

(b)

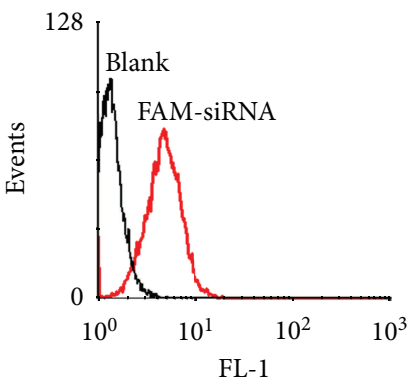

(d)

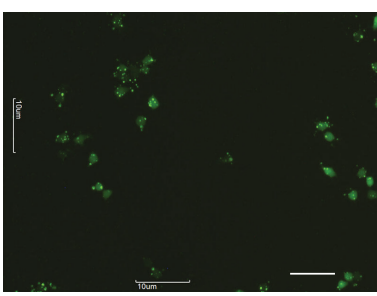

(e)

FIGURE 3: SS-PEI-mediated GFP-siRNA transfection in SGC-7901 cells stably expressing GFP gene and VEGF-siRNA transfection in HepG2 cells in vitro. GFP gene expression (a) and cell viability (b) of SGC-7901 cells after siRNA transfection with SS-PEI/GFP-siRNA at different N/P ratios; (c) The expression of VEGF in HepG2 cells after siRNA transfection with SS-PEI/siRNA complexes at an optimal N/P ratio. Lipofectamine 2000 is used as a positive control; (d) Flow cytometry histogram of HepG2 cells treated with SS-PEI/FAM-siRNA; (e) Fluorescent microscopic images of HepG2 cells treated with SS-PEI/FAM-siRNA. (Scale bar: $50 \mu \mathrm{m}$ ).

It appeared that the highest amount of the SS-PEI was found at about $1 \mathrm{~h}$ of postinjection. After $24 \mathrm{~h}$ of postinjection, this polymer was found mainly accumulated in the liver $(10.6 \pm$ $2 \%)$, spleen $(0.36 \pm 0.1 \%)$, and excretory organ kidneys $(4.3 \pm$ $0.5 \%$ ) (Figures $4(\mathrm{c})$ and $4(\mathrm{~d})$ ).

\subsection{SS-PEI-Delivered VEGF-siRNA Inhibits HepG2 Tumor} Growth In Vivo. In a further study, the activity of SSPEI/VEGF-siRNA complexes against the growth of HepG2 tumors in nude mice was studied. When the tumors reached to approximately $200 \mathrm{~mm}^{3}$, SS-PEI/VEGF-siRNA, $\mathrm{B}-\mathrm{PEI} / \mathrm{siRNA}$, or PBS was respectively injected into the tumors at multiple sites (6 points) every other day for five times. It was seen that the average size of HepG2 tumors became statistically smaller at days $7,14,21$, and $28(P<$ $0.001)$ for the SS-PEI/VEGF-siRNA-treated group compared to the group treated by SS-PEI/siRNA-NC or PBS (Figure 5). Moreover, the complexes of SS-PEI/VEGF-siRNA induced more efficient tumor growth inhibition as compared to those of B-PEI/VEGF-siRNA. To visualize detailed histology of the tumor tissues, hematoxylin and eosin (H\&E), VEGF, and CD34 immunohistochemical staining were performed, respectively (Figure 6). The hematoxylin stains DNA in the cellular nucleus to show the amount of cells. The tumor tissue injected with SS-PEI/VEGF-siRNA has much less purple (stained by hematoxylin) as compared to that treated by BPEI/VEGF-siRNA or PBS as a blank control, implying that SS-PEI/VEGF-siRNA treatment likely inhibits in vivo growth of HepG2 cells. Besides, the expression of VEGF and CD34 in the tumor tissues treated by SS-PEI/VEGF-siRNA was markedly lower than those tumors injected by B-PEI/VEGFsiRNA or PBS as a blank control (Figure 6(c)). These results indicate that SS-PEI/VEGF-siRNA formulation is efficient to inhibit the neoangiogenesis of HepG2 tumor in vivo.

\section{Discussion}

The development of highly potent and low-toxic siRNA delivery carriers is essential for successful siRNA-based cancer therapy. It is generally accepted that high molecular weight branched polyethylenimine (B-PEI, $25 \mathrm{kDa}$ ), a polycation with a large amount of protonable amino groups, is one of the most potent gene delivery carriers because of its strong ability to bind plasmid DNA/siRNA and efficient capability for endosomal escape by so-called "proton sponge effect." However, clinical practice of B-PEI is hampered by the nature of high cytotoxicity, due to the nature of nondegradability. The introduction of the disulfide bonds into PEI can contribute to lower cytotoxicity since disulfide-based polymers are degradable in intracellular reductive environment through the cleavage of the disulfide linkage by the glutathione and 

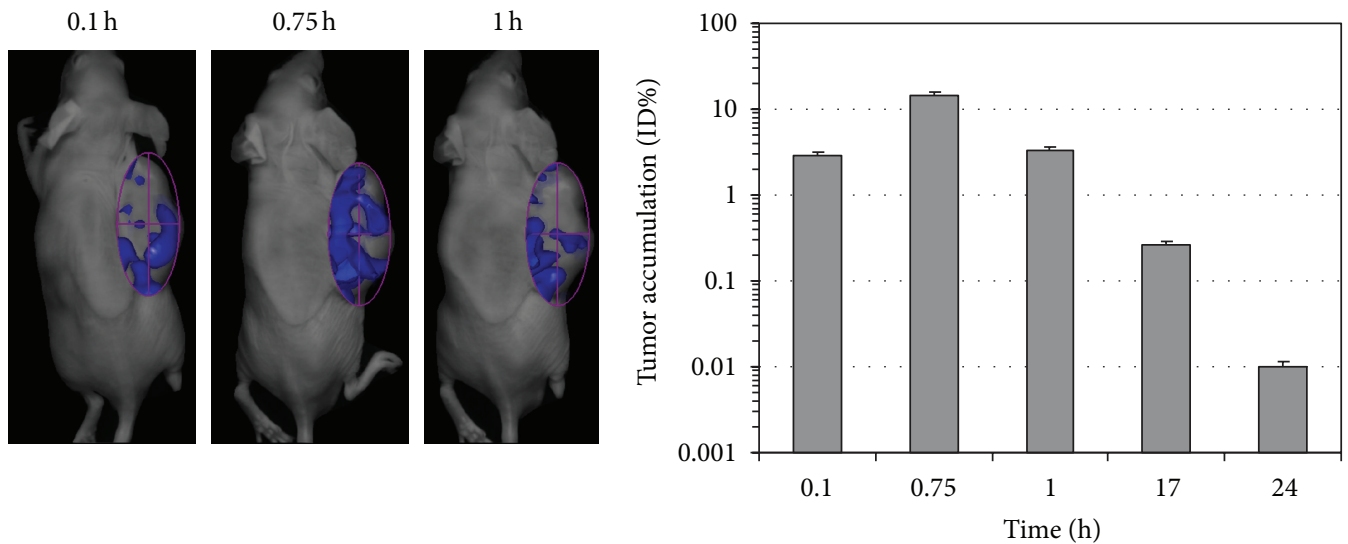

(a)
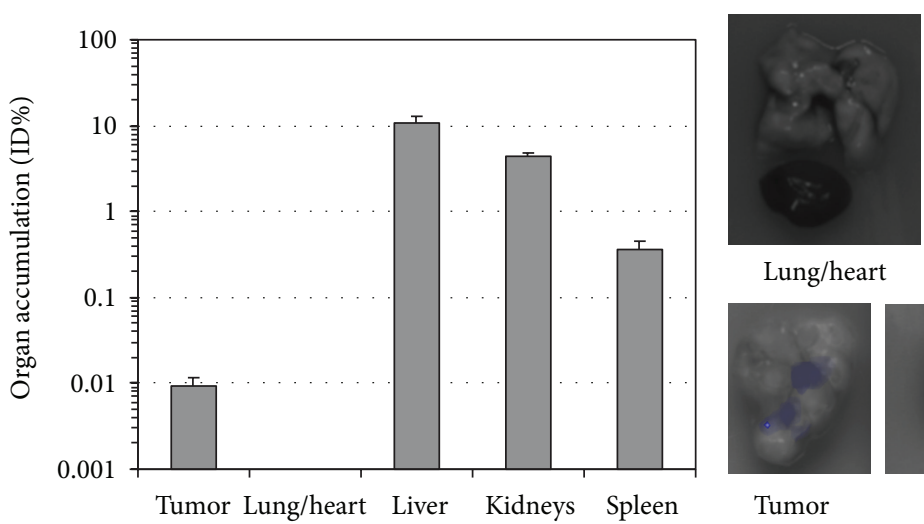

(b)

(c)

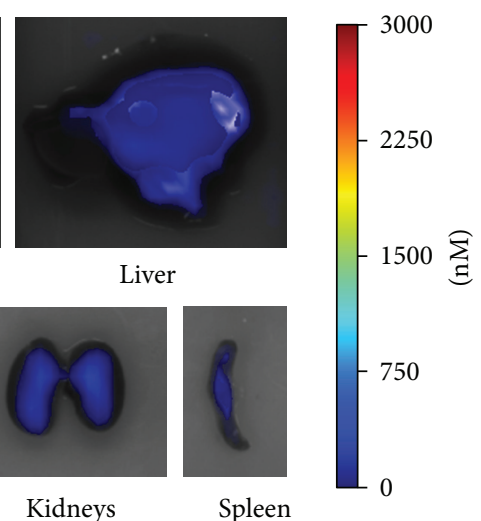

(d)

FIGURE 4: (a) In vivo imaging of Cy5.5-labeled SS-PEI in HepG2 tumor bearing in nude mice at different time intervals; (b) tumor accumulation rate of Cy5.5-labeled SS-PEI after postinjection of its complexes at different time intervals; (c) organ distribution of Cy5.5labeled SS-PEI after postinjection of its complexes at $24 \mathrm{~h}$; (d) Ex vivo imaging of Cy5.5-labeled SS-PEI in organs after postinjection of its complexes at $24 \mathrm{~h}$.

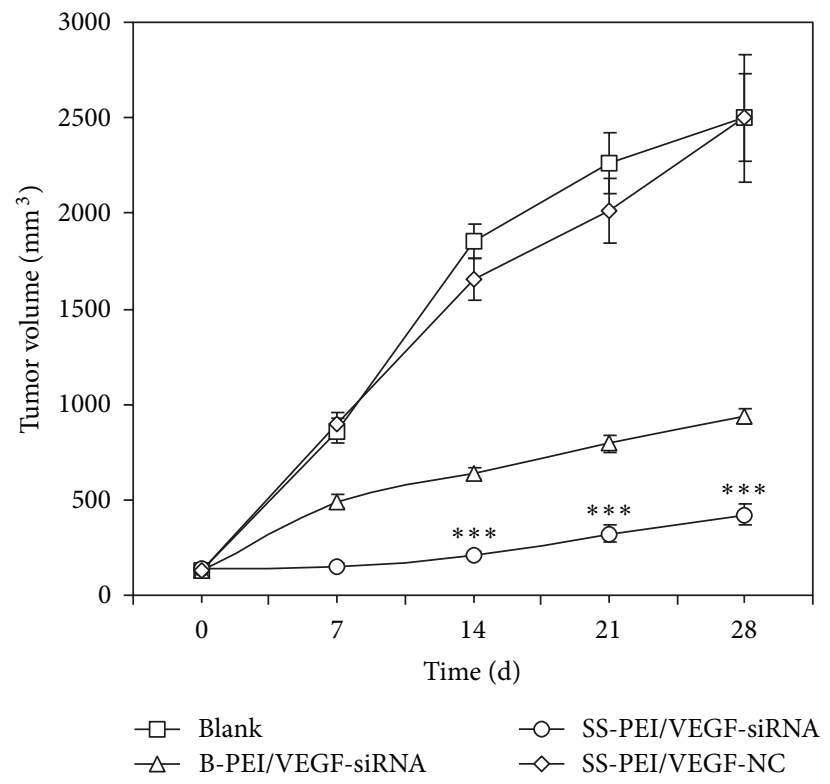

FIGURE 5: Effect of SS-PEI/VEGF-siRNA on growth of HepG2 tumors bearing in nude mice. The tumor dimensions were measured every 7 days and performed in a coded, blinded fashion. Data are shown as mean \pm SD with 5 mice per group, ${ }^{* * *} P<0.001$ : SS-PEI versus blank. 

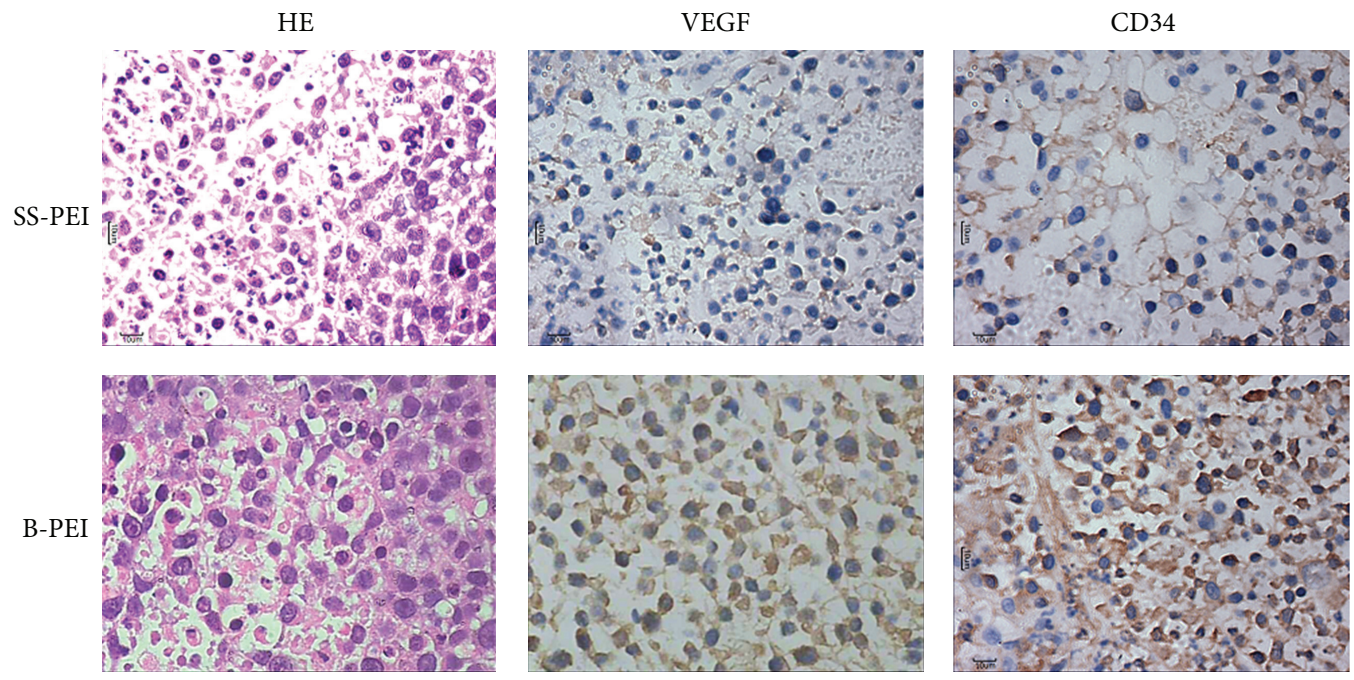

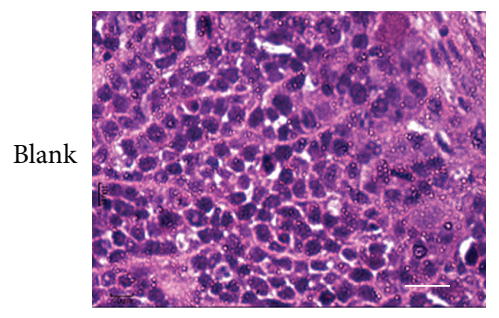

(a)

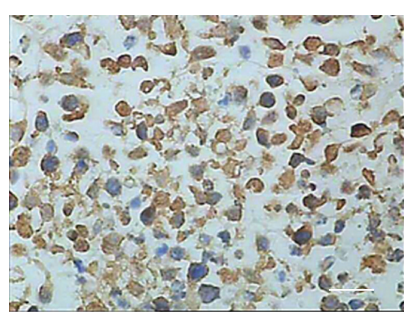

(b)

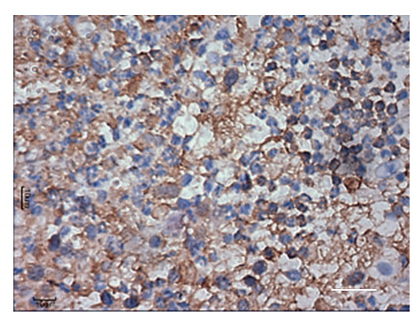

(c)

FIGURE 6: (a) H\&E staining shows growth inhibition of HepG2 cells in tumor tissue after intratumoral injection of SS-PEI/VEGF-siRNA complexes, compared to $25 \mathrm{kDa}$-branched PEI(B-PEI)/siRNA and blank; (b) VEGF staining shows the levels of VEGF protein expression after intratumoral injection of SS-PEI/VEGF-siRNA complexes; (c) CD34 staining shows the levels of CD34 protein expression after the transfection of SS-PEI/VEGF-siRNA. These images are 400x magnifications. (Scale bar: $20 \mu \mathrm{m}$ ).

thioredoxin reductases [21]. The SS-PEI thus has favorable gene delivery properties similar to B-PEI and much lower cytotoxicity than the B-PEI $(25 \mathrm{kDa})$ in HepG2 cells (Figure 2). As expected, the SS-PEI used in this study reveals strong ability to bind plasmid DNA and siRNA. At the N/P ratios from $3 / 1$ to $24 / 1$, the SS-PEI can effectively condense plasmid DNA and siRNA into nanoscale complexes with positive surface charges. This efficient gene binding activity may benefit from the presence of protonable amino groups in SSPEI. In addition, it has been showed in our previous report that gene and siRNA could be adequately released from SSPEI-based complexes in the presence of a reducing agent dithiothreitol (DTT), mimicking an intracellular reductive environment [22-24], implying intracellular unpacking of the complexes and efficient gene/siRNA release inside cells. Overall, these favorable biophysical properties of SS-PEI, including a low cytotoxicity profile, strong gene binding ability, and intracellular release of nucleic acid cargoes, may be the reason why SS-PEI mediates efficient intracellular delivery of gene cargoes, giving rise to a high level of gene expression (Figure 2) and gene silencing in vitro (Figure 3 ).

Angiogenesis is an essential process in an advanced stage of HCC tumor, where the vascular endothelial growth factor (VEGF) is one of the most powerful angiogenic factors. The growth of HCC cells like HepG2 cells needs an adequate vascular network for the supply of oxygen and nutrients. For these reasons, when the VEGF level in the tumor is reduced through SS-PEI-mediated VEGF gene silencing, the inhibition process should be followed by decreased neo-microvasculature formation. To support this idea, we detected CD34, an endothelial antigen, which is generally regarded as a bio-marker of the degree of neoangiogenesis to characterize the vasculature vessel density. As we expected, a lower expression level of CD34 in tumor section was observed after being treated with SS-PEI/VEGF-siRNA (Figure 5).

A further study is needed to ascertain whether the SSPEI can be used for systemic intravenous delivery of VEGFsiRNA. The data from the organ distribution study show that the SS-PEI is generally accumulated in the liver and kidneys after $24 \mathrm{~h}$ of i.v. administration of Cy5.5-labeled SS$\mathrm{PEI} / \mathrm{siRNA}$ complexes by tail-vein injection (Figure 4(c)). The dominant retention in the liver is caused by the opsonization of the complexes, since negatively charged antibody tends to bind with positively charged complexes in the bloodstream and subsequently, opsonized complexes are recognized by the phagocytic system [25]. In this study, we only demonstrate that the treatment with the complexes of SS-PEI/VEGF siRNA can inhibit tumor growth by intratumoral injection of the complexes. To weaken the undesirable accumulation in the liver and obtain long-term circulation of the complexes 
in vivo, a further chemical modification, for example, PEGylation of SS-PEI is highly needed to generate the complexes with a "stealth" property $[26,27]$.

\section{Conclusion}

We have demonstrated that a disulfide-based polyethylenimine (SS-PEI) can be successfully applied for the delivery of plasmid DNA and VEGF-siRNA in vitro and in vivo. The complexes of SS-PEI/VEGF-siRNA may efficiently inhibit VEGF expression in HepG2 cells in vitro and vivo and the neoangiogenesis of HepG2 tumor in vivo. Thus, SS-PEIinduced VEGF gene silencing has a high potential for HCC gene therapy. Presently, ongoing work at our group is to chemically modify SS-PEI with PEG and homing devices for targeted VEGF-siRNA delivery in vivo.

\section{Authors' Contribution}

The authors contributed equally as co-first authors W. Xia and Y. Li.

\section{Acknowledgments}

This work was financially supported by the National Natural Science Foundation of China (no. 20904041, C. Lin No.81071201, P. Wang), the Key Scientific Project of Shanghai Putuo District (PTKW10-B01, W. Xia), Fundamental Research Funds for the Central Universities (C. Lin), the Innovation Program of Shanghai Municipal Education Commission (no. 10ZZ26, C.L.), the Scientific Research Foundation for the Returned Overseas Chinese Scholars, State Education Ministry.

\section{References}

[1] W. Y. Lau, "Primary liver tumors," Seminars in Surgical Oncology, vol. 19, no. 2, pp. 135-144, 2000.

[2] K. Okuda, "Hepatocellular carcinoma," Journal of Hepatology, vol. 32, no. 1, pp. 225-237, 2000.

[3] I. O. L. Ng, R. T. P. Poon, J. M. F. Lee, S. T. Fan, M. Ng, and W. K. Tso, "Microvessel density, vascular endothelial growth factor and its receptors Flt-1 and Flk-1/KDR in hepatocellular carcinoma," American Journal of Clinical Pathology, vol. 116, no. 6, pp. 838-845, 2001.

[4] R. Yamaguchi, H. Yano, A. Iemura, S. Ogasawara, M. Haramaki, and M. Kojiro, "Expression of vascular endothelial growth factor in human hepatocellular carcinoma," Hepatology, vol. 28, no. 1, pp. 68-77, 1998.

[5] H. P. Gerber, V. Dixit, and N. Ferrara, "Vascular endothelial growth factor induces expression of the antiapoptotic proteins Bcl-2 and A1 in vascular endothelial cells," Journal of Biological Chemistry, vol. 273, no. 21, pp. 13313-13316, 1998.

[6] T. Takahashi, H. Ueno, and M. Shibuya, "VEGF activates protein kinase C-dependent, but Ras-independent Raf-MEKMAP kinase pathway for DNA synthesis in primary endothelial cells," Oncogene, vol. 18, no. 13, pp. 2221-2230, 1999.

[7] M. Shibuya, "Structure and function of VEGF/VEGF-receptor system involved in angiogenesis," Cell Structure and Function, vol. 26, no. 1, pp. 25-35, 2001.
[8] G. R. Devi, "siRNA-based approaches in cancer therapy," Cancer Gene Therapy, vol. 13, no. 9, pp. 819-829, 2006.

[9] J. H. Jeong, L. V. Christensen, J. W. Yockman et al., "Reducible poly(amido ethylenimine) directed to enhance RNA interference," Biomaterials, vol. 28, no. 10, pp. 1912-1917, 2007.

[10] E. Raskopf, A. Vogt, T. Sauerbruch, and V. Schmitz, "siRNA targeting VEGF inhibits hepatocellular carcinoma growth and tumor angiogenesis in vivo," Journal of Hepatology, vol. 49, no. 6, pp. 977-984, 2008.

[11] Y. K. Oh and T. G. Park, "siRNA delivery systems for cancer treatment," Advanced Drug Delivery Reviews, vol. 61, no. 10, pp. 850-862, 2009.

[12] D. J. Gary, N. Puri, and Y. Y. Won, "Polymer-based siRNA delivery: perspectives on the fundamental and phenomenological distinctions from polymer-based DNA delivery," Journal of Controlled Release, vol. 121, no. 1-2, pp. 64-73, 2007.

[13] C. Boyer, P. Priyanto, T. P. Davis et al., "Anti-fouling magnetic nanoparticles for siRNA delivery," Journal of Materials Chemistry, vol. 20, no. 2, pp. 255-265, 2010.

[14] O. Boussif, F. Lezoualch, M. A. Zanta et al., "A versatile vector for gene and oligonucleotide transfer into cells in culture and in vivo: polyethylenimine," Proceedings of the National Academy of Sciences of the United States of America, vol. 92, no. 16, pp. 7297-7301, 1995.

[15] W. Xia, P. Wang, C. Lin et al., "Bioreducible polyethyleniminedelivered siRNA targeting human telomerase reverse transcriptase inhibits HepG2 cell growth in vitro and in vivo," Journal of Controlled Release, vol. 157, no. 3, pp. 427-436, 2012.

[16] W. Xia and C. Lin, "Bioreducible polymer-delivered siRNA targeting human telomerase reverse transcriptase for human cancer gene therapy," Therapeutic Delivery, vol. 3, no. 4, pp. 439-442, 2012.

[17] C. Lin and J. F. J. Engbersen, "PEGylated bioreducible poly(amido amine)s for non-viral gene delivery," Materials Science and Engineering C, vol. 31, no. 7, pp. 1330-1337, 2011.

[18] Y. Y. Sun, Z. F. Deng, Y. Tian, and C. Lin, "Horseradish peroxidase-mediated in situ forming hydrogels from degradable tyramine-based poly(amido amine)s," Journal of Applied Polymer Science, vol. 127, no. 1, pp. 40-48, 2013.

[19] C. Lin and J. P. Ge, "Multifunctional polyethylenimineconjugated superparamagnetic nanoparticles for drug delivery and imaging," Journal of Controlled Release, vol. 152, supplement 1, pp. e58-e60, 2011.

[20] F. Li, Q. J. Ba, S. M. Niu et al., "In-situ forming biodegradable glycol chitosan-based hydrogels: synthesis, characterization, and chondrocyte culture," Materials Science \& Engineering C, vol. 32, no. 7, pp. 2017-2025, 2012.

[21] C. Lin and J. F. J. Engbersen, "The role of the disulfide group in disulfide-based polymeric gene carriers," Expert Opinion on Drug Delivery, vol. 6, no. 4, pp. 421-439, 2009.

[22] C. Lin, Z. Zhong, M. C. Lok et al., "Novel bioreducible poly(amido amine)s for highly efficient gene delivery," Bioconjugate Chemistry, vol. 18, no. 1, pp. 138-145, 2007.

[23] C. Lin, C.-J. Blaauboer, M. M. Timoneda et al., "Bioreducible poly(amido amine)s with oligoamine side chains: synthesis, characterization, and structural effects on gene delivery," Journal of Controlled Release, vol. 126, no. 2, pp. 166-174, 2008.

[24] C. Lin, Z. Y. Zhong, M. C. Lok et al., "Linear poly(amido amine)s with secondary and tertiary amino groups and variable amounts of disulfide linkages: synthesis and in vitro gene transfer properties," Journal of Controlled Release, vol. 116, no. 2, pp. 130-137, 2006. 
[25] C. Plank, K. Mechtler, F. C. Szoka, and E. Wagner, "Activation of the complement system by synthetic DNA complexes: a potential barrier for intravenous gene delivery," Human Gene Therapy, vol. 7, no. 12, pp. 1437-1446, 1996.

[26] S. Son, K. Singha, and W. J. Kim, "Bioreducible BPEI-SS-PEGcNGR polymer as a tumor targeted nonviral gene carrier," Biomaterials, vol. 31, no. 24, pp. 6344-6354, 2010.

[27] S. Son and W. J. Kim, "Biodegradable nanoparticles modified by branched polyethylenimine for plasmid DNA delivery," Biomaterials, vol. 31, no. 1, pp. 133-143, 2010. 

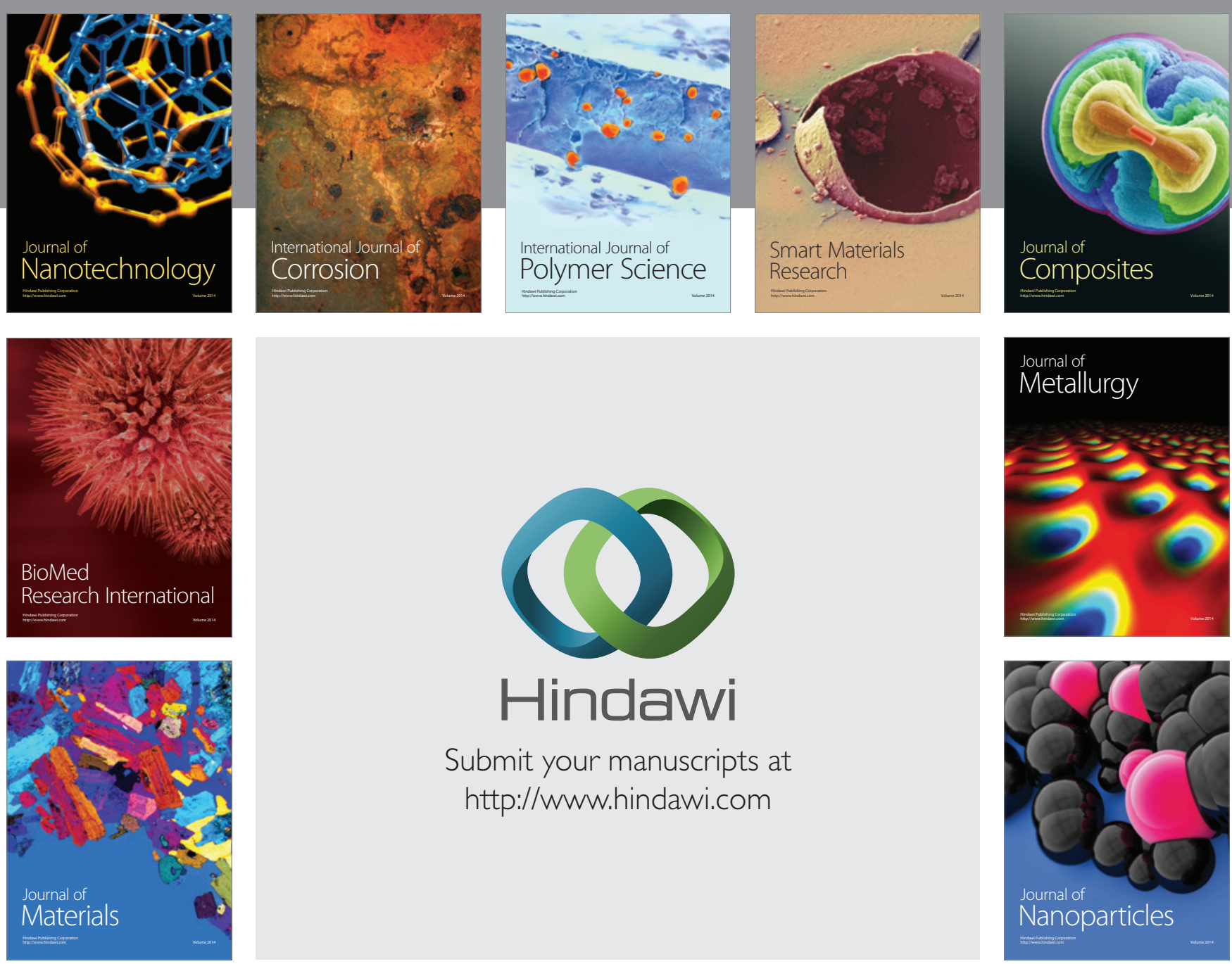

Submit your manuscripts at http://www.hindawi.com
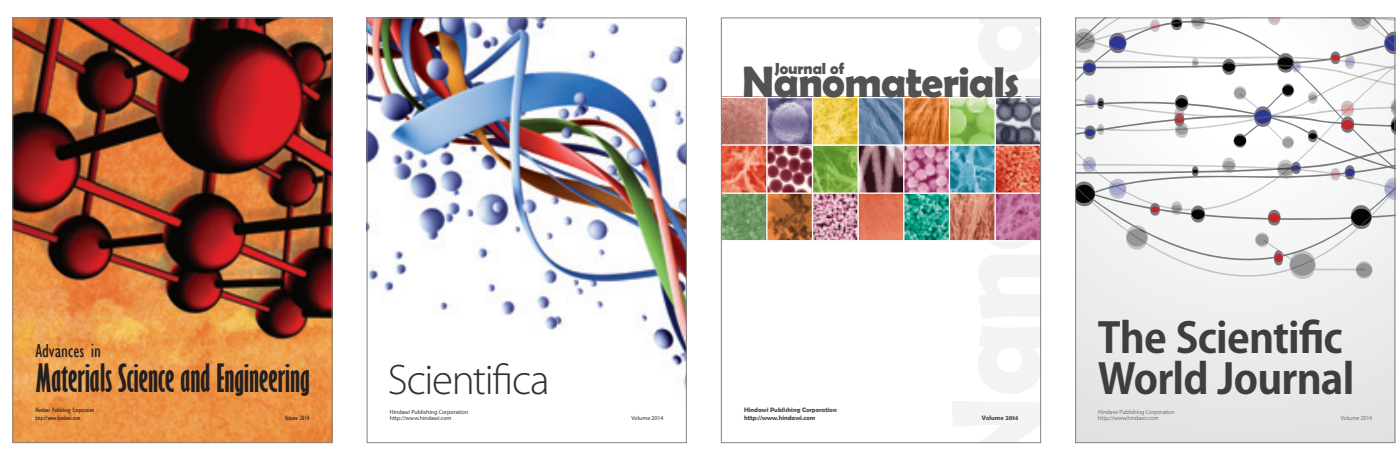

\section{The Scientific World Journal}
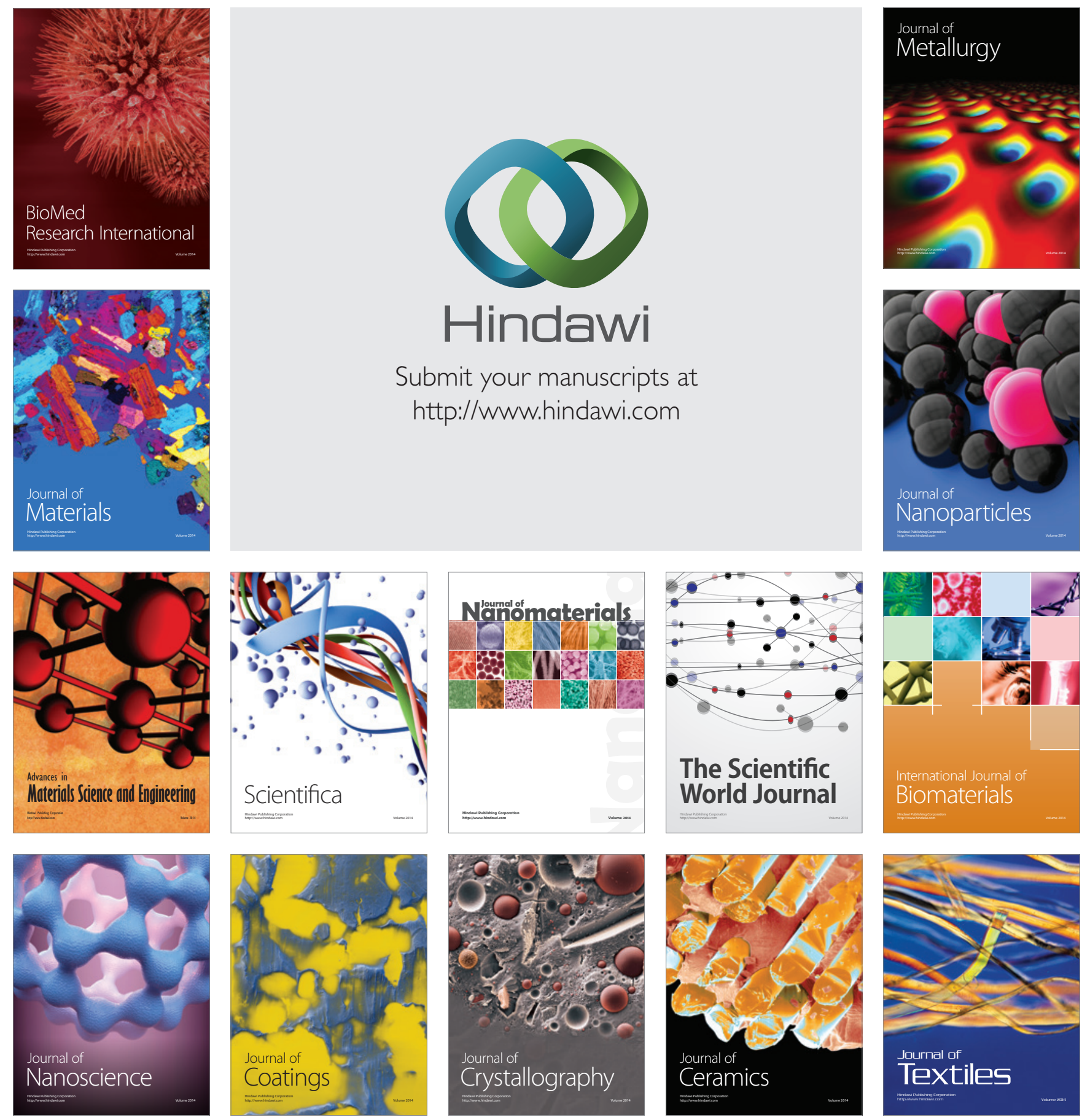